\title{
Metastatic gastric tumors arising from renal cell carcinoma: Clinical characteristics and outcomes of this uncommon disease
}

\author{
TSUTOMU NAMIKAWA ${ }^{1}$, MASAYA MUNEKAGE ${ }^{1}$, HIROYUKI KITAGAWA ${ }^{1}$, \\ TAKEHIRO OKABAYASHI ${ }^{1}$, MICHIYA KOBAYASHI ${ }^{2}$ and KAZUHIRO HANAZAKI ${ }^{1}$
}

Departments of ${ }^{1}$ Surgery and ${ }^{2}$ Human Health and Medical Sciences, Kochi Medical School, Kochi 783-8505, Japan

Received April 2, 2012; Accepted July 11, 2012

DOI: $10.3892 / 01.2012 .807$

\begin{abstract}
We analyzed the clinicopathological characteristics and therapeutic outcomes of patients with metastatic gastric tumors arising from renal cell carcinoma (RCC) to identify post-therapy prognostic factors. A total of 22 patients who were treated for metastatic gastric tumors arising from $\mathrm{RCC}$ were included in the study. A retrospective review was performed on the clinical characteristics of this disease. The median time interval from radical excision of the primary tumor to the detection of gastric metastasis (IGM) was 6.3 years. The overall 1- and 3-year survival rates were 52.6 and $21.0 \%$, respectively, and the median survival time was 19 months. Compared with patients with an IGM of $<6.3$ years, patients with an IGM of $\geq 6.3$ years showed a significantly longer median survival time (5 vs. 24 months; $\mathrm{P}=0.017$ ). The median tumor size was significantly greater in patients with multiple metastases compared with those with solitary metastasis ( 4 vs. $2 \mathrm{~cm} ; \mathrm{P}=0.036$ ). The incidence of patients who had undergone therapeutic tumor resection was significantly higher in patients with solitary metastasis compared with those with multiple metastases ( 100.0 vs. $35.7 \%$; $\mathrm{P}=0.019)$. The appearance of gastric tumors in patients with a history of RCC should prompt the clinician to investigate the possibility of metastasis even several years after detection of the original renal cancer. A longer interval from nephrectomy to the diagnosis of gastric metastasis is generally indicative of a better prognosis, most likely the result of less aggressive tumor growth.
\end{abstract}

\section{Introduction}

Based on clinical and autopsy findings, the stomach is an unusual site for metastasis and the reported incidence of

Correspondence to: Dr Tsutomu Namikawa, Department of Surgery, Kochi Medical School, Kohasu, Oko-cho, Nankoku, Kochi 783-8505, Japan

E-mail: tsutomun@kochi-u.ac.jp

Key words: gastric metastasis, renal cell carcinoma, metastatic tumor, surgery, outcome metastatic gastric tumors is $0.2-0.7 \%$ (1-3). Metastatic spread to the stomach may occur a number of years after the initial treatment of the primary malignancy. The breast, melanoma, lung and esophagus are the most common primary sites of metastases to the stomach (2-4). The most common sites of metastasis in renal cell carcinoma (RCC), which accounts for 2 to $3 \%$ of adult malignant neoplasms, are the lung (75\%), lymph nodes (36\%), bone (20\%) and liver (18\%) (5). RCC is known to cause metastatic recurrences a number of years after its resection and even after immunotherapy or molecularly targeted therapy. Whereas the gastrointestinal tract is a rare site for metastases of RCC, rare sites of metastasis, including the thyroid, pancreas, skeletal muscles and skin, are characteristic of RCC $(5,6)$.

As gastric metastasis is a rare condition, information on gastric metastases is generally limited to single case reports and there are no reported prognostic outcomes. Our searches of English literature on gastric metastases arising from RCC in MEDLINE revealed only 22 studies, including a case treated in our hospital, with clearly presented data. In the present study, we reviewed the clinical presentation, surgical management and prognostic factors of metastatic gastric tumors arising from RCC.

\section{Materials and methods}

Literature search. We performed a search of English literature published between 1970 and 2011 in MEDLINE and PubMed for articles on metastatic gastric tumors arising from RCC using the keywords 'gastric metastasis' and 'renal cell carcinoma'. The reference lists of the articles identified in this manner were then manually searched to identify any additional references and articles published only in abstract form were excluded. From this search, we identified 22 cases of gastric metastases arising from RCC (1,5,7-22).

We reviewed 22 patients who were diagnosed with gastric metastases arising from RCC, including one patient who was treated in our hospital. For each patient, we obtained data on age, gender, tumor location, tumor size, metastases to other organs, histological type, the time interval between radical excision of the primary tumor and the diagnosis of gastric metastasis (IGM), treatment method and outcome. We analyzed these data to identify possible correlations between clinical variables and survival. 
Statistical analysis. We used the Mann-Whitney U test to evaluate correlations among the continuous variables for each group and Pearson's Chi-square test to compare the categorical variables. We used the Kaplan-Meier method to generate cumulative survival rates and compared them using the log-rank test to evaluate statistically significant differences (23). $\mathrm{P}<0.05$ was considered to indicate a statistically significant result. Statistical analysis was performed using SPSS for Windows version 13.0 (SPSS, Inc., Chicago, IL, USA).

\section{Results}

Clinical characteristics. The clinical features of the 22 reported cases are listed in Table I. The median age of the patients was 68 years (range, 48-83) and there was a male predominance, with a male-to-female ratio of 16:5. Among these patients, 6 had lesions in the upper third of the stomach, 10 had lesions in the middle third and 6 had lesions in the lower third. The tumor size ranged from 1 to $8 \mathrm{~cm}$ (median, $3 \mathrm{~cm}$ ). Based on gross appearance, we divided the tumors into ulcerated and protruding types. Examination of the tumors revealed 7 cases with the ulcerated type and 11 cases with the protruding type. Symptoms associated with bleeding of the tumors, such including melena, hematemesis or anemia, were observed in 18 cases $(81.8 \%)$.

The median IGM was 6.3 years (range, 1-23). The case with the maximal interval of 23 years was the patient treated in our hospital. The RCCs were clear-cell carcinomas in all cases. A total of 7 cases had solitary gastric metastasis and 14 cases had metastases in other locations. Among the 14 cases with metastases in other locations, tumors were found in the lung in 8 cases, bone in 4 cases, liver in 3 cases, pancreas in 2 cases and in the brain, esophagus, duodenum, spleen, peritoneum and paraaortic lymph nodes in 1 case each. Treatment included wedge resection, gastrectomy and endoscopic resection in 12 cases and palliative therapy in 9 cases due to the general condition of the patients and the presence of additional metastases.

Survival analysis. The median survival time was 19 months (range, 1 to 36) and the overall 1- and 3-year survival rates after therapy were 52.6 and $21.0 \%$, respectively (Fig. 1). Clinical characteristics of patients with metastatic gastric tumors arising from RCC are shown in Table II, together with a comparison of survival rates among subgroups of prognostic factors. The median survival period of patients with a protruding type tumor was significantly worse than those with an ulcerated type tumor (5 vs. 24 months; $\mathrm{P}=0.030$ ). When patients were divided into two groups depending on the IGM (i.e., $<6.3$ or $\geq 6.3$ years), median survival was 5 months for patients with an IGM $<6.3$ years compared with 24 months for those with an IGM $\geq 6.3$ years ( $\mathrm{P}=0.017$; Fig. 2 ). A short interval between initial radical excision of the primary tumor and appearance of gastric metastasis was found to be significantly associated with a poor outcome. The 3 -year survival rate of patients with a tumor $<3 \mathrm{~cm}$ in diameter tended to be higher than those with a tumor in $\geq 3 \mathrm{~cm}$ diameter ( 72.9 vs. $11.1 \%$ ), although the differences did not reach statistical significance $(\mathrm{P}=0.067)$. There were no significant influences on survival rate by age, gender, tumor location, bleeding, metastasis type

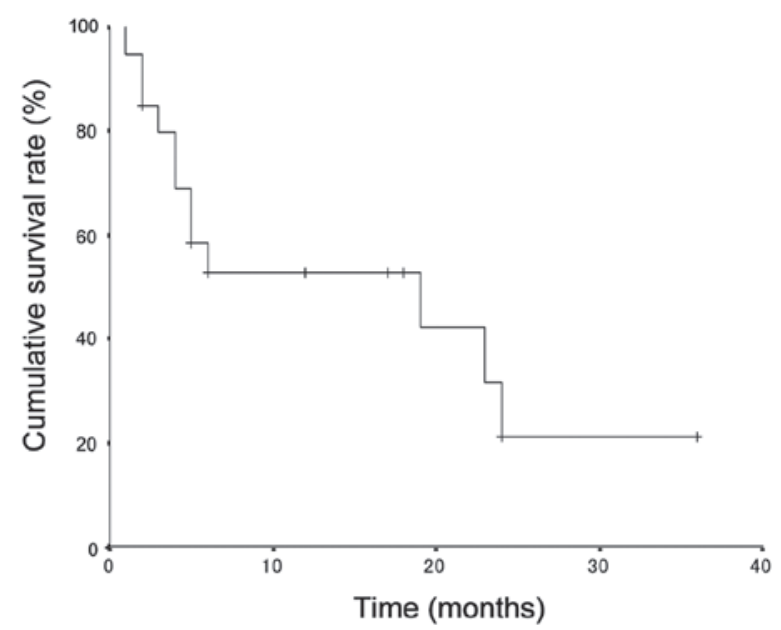

Figure 1. Survival curves of 22 patients with metastatic gastric tumors arising from renal cell carcinoma.

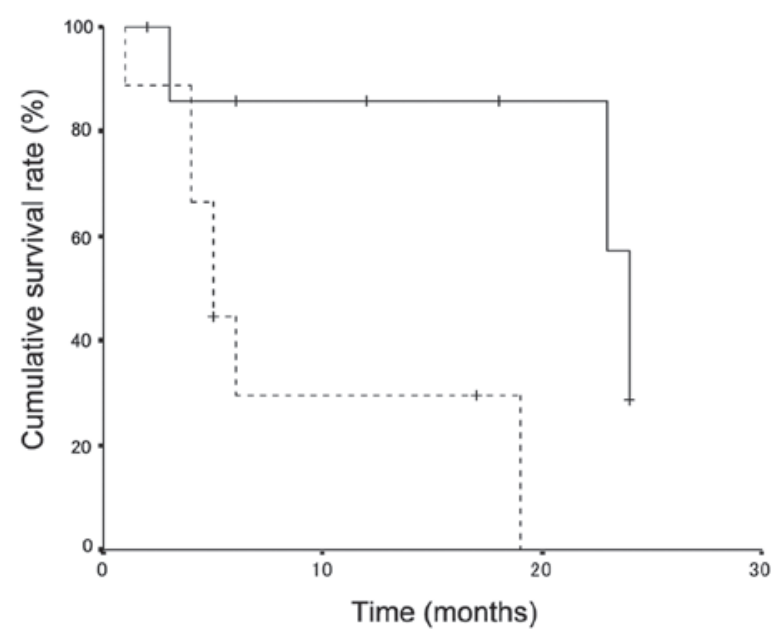

Figure 2. Survival curves of 9 patients with metastatic gastric tumors diagnosed $\geq 6.3$ years after radical excision of the primary tumor (solid line) and those for 10 patients with metastatic gastric tumors diagnosed $<6.3$ years of radical excision of the primary tumor (dotted line). There was a significant difference in survival between the two groups $(\mathrm{P}=0.017)$. $\mathrm{P}$-values were calculated using the stratified log-rank test.

or method of therapy. No independent prognostic factors were identified by multivariate analysis, probably due to the small patient number.

Comparison of solitary and multiple metastases. Table III shows a comparison of clinical characteristics between solitary and multiple metastases of 22 patients with metastatic gastric tumors arising from RCC. The median tumor size was significantly greater in patients with multiple metastases than in those with solitary metastasis ( 4 vs. $2 \mathrm{~cm} ; \mathrm{P}=0.036$ ). The incidence of tumor resection performed as therapy was significantly higher in patients with solitary metastasis than in those with multiple metastases (100.0 vs. $35.7 \% ; \mathrm{P}=0.019$ ). There were no significant differences in age, gender, tumor location or the IGM between solitary metastasis and multiple metastases. 


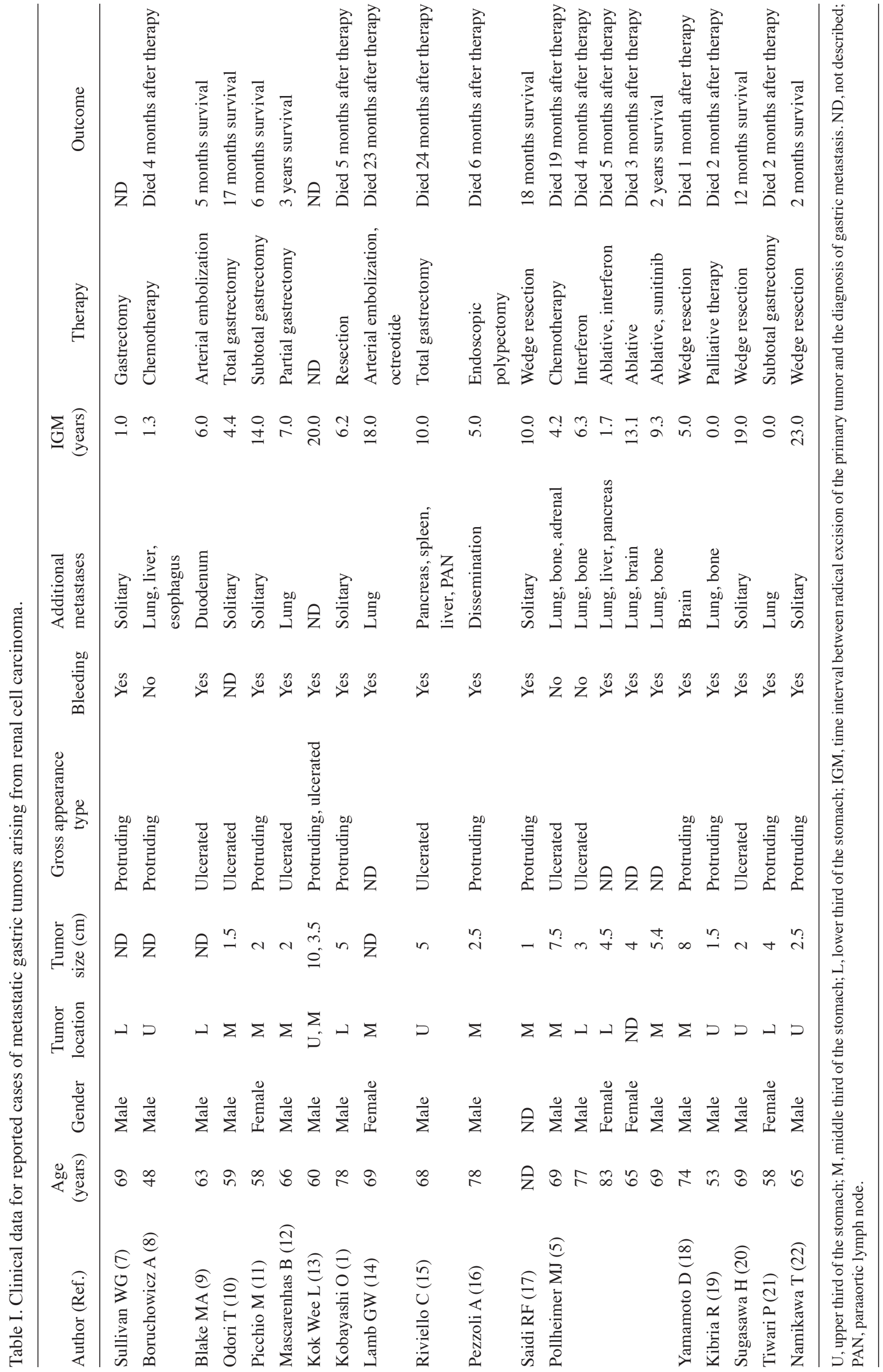


Table II. Clinical characteristics of patients following treatment of metastatic gastric tumors arising from renal cell carcinoma.

\begin{tabular}{|c|c|c|c|}
\hline Characteristics & $\begin{array}{c}\text { 3-year survival } \\
\text { rate }(\%)\end{array}$ & $\begin{array}{l}\text { Median survival } \\
\text { time (months) }\end{array}$ & P-value \\
\hline Overall & 21 & 19 & \\
\hline Age (years) & & & 0.631 \\
\hline$<68$ & 28.6 & 24 & \\
\hline$\geq 68$ & 14.8 & 6 & \\
\hline Gender & & & 0.345 \\
\hline Male & 26.7 & 19 & \\
\hline Female & 0 & 5 & \\
\hline Tumor location & & & 0.102 \\
\hline Upper third & 0 & 24 & \\
\hline Middle third & 38.9 & 23 & \\
\hline Lower third & 20 & 5 & \\
\hline Tumor size (cm) & & & 0.067 \\
\hline$<3$ & 72.9 & - & \\
\hline$\geq 3$ & 11.1 & 5 & \\
\hline \multicolumn{2}{|c|}{ Gross appearance type } & & 0.030 \\
\hline Ulcerated & 28.6 & 24 & \\
\hline Protruding & 26.7 & 5 & \\
\hline Bleeding & & & 0.366 \\
\hline Yes & 26.7 & 23 & \\
\hline No & 0 & 4 & \\
\hline Metastasis & & & 0.133 \\
\hline Solitary & - & - & \\
\hline Multiple & 16.7 & 5 & \\
\hline IGM (years) & & & 0.017 \\
\hline$<6.3$ & 0 & 5 & \\
\hline$\geq 6.3$ & 28.6 & 24 & \\
\hline Therapy & & & 0.318 \\
\hline Resection & 30.7 & 24 & \\
\hline Palliative & 14.8 & 5 & \\
\hline
\end{tabular}

IGM, time interval between radical excision of the primary tumor and the diagnosis of gastric metastasis.

\section{Discussion}

This study demonstrated that the median IGM of the 22 patients with RCC metastasis to the stomach was 6.3 years (range, 1-23), meaning that most patients with primary renal cancer present with metastasis in the stomach several years after the initial diagnosis and treatment of their original primary cancer. To date, there are no published studies investigating the treatment of patients with metastatic gastric tumors following curative resection for RCC. The particularly noteworthy finding in the present study was that patients with an IGM $<6.3$ years had a significantly poorer prognosis than those with an $\mathrm{IGM} \geq 6.3$ years.

The time interval between diagnosis of the primary tumor and diagnosis of gastric metastasis is reported to be
Table III. Comparison of clinical characteristics between solitary metastasis and multiple metastases arising from renal cell carcinoma.

\begin{tabular}{|c|c|c|c|}
\hline Characteristics & $\begin{array}{l}\text { Solitary } \\
\text { metastasis }\end{array}$ & $\begin{array}{c}\text { Multiple } \\
\text { metastases }\end{array}$ & P-value \\
\hline $\begin{array}{l}\text { Age (years), } \\
\text { mean (range) }\end{array}$ & $67(58-78)$ & $68(48-83)$ & 0.933 \\
\hline Gender, $\mathrm{n}$ & & & 0.573 \\
\hline Male & 5 & 10 & \\
\hline Female & 1 & 4 & \\
\hline Tumor location, $\mathrm{n}$ & & & 0.964 \\
\hline Upper third & 2 & 3 & \\
\hline Middle third & 3 & 6 & \\
\hline Lower third & 2 & 4 & \\
\hline $\begin{array}{l}\text { Median tumor size } \\
(\mathrm{cm}), \text { mean (range) }\end{array}$ & $2(1-5)$ & $4(1.5-8)$ & 0.036 \\
\hline $\begin{array}{l}\text { Median IGM (years), } \\
\text { mean (range) }\end{array}$ & $10(1-23)$ & $6.2(1.3-20)$ & 0.447 \\
\hline Therapy, n & & & 0.019 \\
\hline Resection & 7 & 5 & \\
\hline Palliative & 0 & 9 & \\
\hline Outcome, $\mathrm{n}$ & & & 0.036 \\
\hline Survived & 5 & 3 & \\
\hline Succumbed to disease & 1 & 11 & \\
\hline
\end{tabular}

IGM, time interval between radical excision of the primary tumor and the diagnosis of gastric metastasis.

1.3-2.1 years for all metastatic gastric tumors arising from melanoma, breast and lung cancers $(4,24)$. It has been reported that the majority of gastric metastases arising from lung cancer and malignant melanoma were detected within 2 years, most likely due to the rapid progression of these malignant tumors $(2,4)$. By comparison, the time interval between the diagnosis of primary breast cancer and diagnosis of gastric metastasis was reported to be 4.0-6.5 years and the median survival period following treatment of these metastases was 10-20 months $(25,26)$. Consistent with these findings was our finding in the present study that the IGM was 6.3 years for gastric metastasis arising from RCC and that the median survival period following treatment was 19 months. Taken together, these results suggest that since metastatic gastric tumors arising from RCC and those arising from breast cancer are slow growing, there may be similarities in the clinical characteristics associated with these cancers.

The present study also confirms the potential of RCC to lead to resectable solitary stomach metastasis, which comprise $31.8 \%$ of all metastatic gastric tumors arising from RCC. Although RCC spreads hematogenously and is known for its ubiquitous metastatic patterns, solitary stomach tumors arising from RCC metastasis is rare. Surgical resection is the preferred treatment for solitary metastasis in the absence of contraindication related to the general state (27). In the 
present study, patients with solitary gastric metastasis arising from RCC had good outcomes following treatment compared with those with multiple metastases. All patients with solitary gastric metastasis underwent surgical resection of the tumor compared with only $35.7 \%$ of those with multiple metastases. It is possible that surgical resection of solitary gastric metastases arising from RCC contributes to the long-term survival of patients.

The clinical presentation of metastatic gastric tumors is often asymptomatic or non-specific unless the metastases invade the gastric mucosa or serosa (1). In cases of gastric metastasis arising from breast cancer, the incidence of hemorrhaging has been reported to be 12 to $33 \%(25,26)$. In the present study, gastrointestinal bleeding as the presenting symptom, together with melena or severe anemia, was observed in $81.8 \%$ of cases. The increased incidence of gastrointestinal bleeding in gastric metastases arising from RCC compared with those arising from breast cancer is most likely due to the fragile and hypervascular nature of RCC.

Although gastric metastases may be recognized as abnormalities on esophagogastroduodenoscopy (EGD), there are no characteristic appearances that define this disease due to the variable morphology of the tumors (28). Frequent endoscopic patterns include volcano-like ulcers, multiple nodules, bull's eye appearance, extrinsic mass lesions, ulceration and polypoid tumor masses $(4,25)$. Based on gross appearance, we divided metastatic gastric tumors into ulcerated and protruding types and found that $50 \%$ were of the protruding type. Gastric metastases arising from breast cancer are readily recognized as a diffuse infiltration, such as linitis plastica or type 4 advanced gastric cancers, at EGD, but are not always confirmed by endoscopic biopsies (25). Gastric tumors usually metastasize to other gastrointestinal organs by a hematogeneous route, lymphatic spread or direct invasion, resulting in submucosal masses. Tumor cells in the blood may become trapped in the submucosal layer of the stomach and develop as submucosal tumors (3). In gastric metastasis arising from $\mathrm{RCC}$, the protruding type tumors which invade to the mucosa may be associated with hemorrhaging.

The choice of systemic treatment of metastatic tumors is based upon presenting symptoms, age, general performance status and previous systemic treatments. Metastatic breast cancer with gastrointestinal tract involvement is evidence of a systemic disease and therefore systemic therapy, such as chemotherapy and/or hormonal therapy, rather than surgical resection is advised (25). Surgical resection is not advised for the treatment of gastric metastasis arising from breast cancer and surgical palliation is only indicated in emergency conditions to bypass obstructions in carefully selected patients (26). Molecular agents targeting metastatic $\mathrm{RCC}$, including sorafenib and sunitinib, mark the start of a new era in the management of the disease with the potential to improve progression-free survival, objective response rate and quality of life (29). However, when managing patients with metastatic gastric tumors, it is important to be aware of the risk of bleeding and tumor perforation during systemic chemotherapy (30). Surgical resection of metastatic gastric tumors may be recommended to control hemorrhaging and therefore result in improved quality of life; however, long-term survival is rare.
The limitations of the present study include the errors and biases inherent in a small retrospective study design. Another limitation is the lack of consistency within the study for treatment following recurrence of the disease, as the choice of treatment for each case was made independently by each physician. Since the prognosis of cancer patients is gradually improving, it is likely that gastrointestinal metastases will be encountered more frequently in the future. For this reason, special attention should be paid to the possibility of recurrence of RCC regardless of the time interval since nephrectomy. While surgical intervention, such as wedge resection of the stomach to reduce surgical stress, is considered to be the best approach to prevent bleeding and improve the postoperative quality of life of patients, it is difficult to conduct prospective studies to provide evidence in support of this approach due to the rarity of gastrointestinal metastases.

In conclusion, the results of this current study suggest that IGM is an important factor in predicting the prognosis of gastrointestinal metastases, regardless of whether surgical resection of the tumor is performed.

\section{References}

1. Kobayashi O, Murakami H, Yoshida T, et al: Clinical diagnosis of metastatic gastric tumors: clinicopathologic findings and prognosis of nine patients in a single cancer center. World J Surg 28: 548-551, 2004.

2. Green LK: Hematogenous metastases to the stomach. A review of 67 cases. Cancer 65: 1596-1600, 1990.

3. Menuck LS and Amberg JR: Metastatic disease involving the stomach. Am J Dig Dis 20: 903-913, 1975.

4. De Palma GD, Masone S, Rega M, et al: Metastatic tumors to the stomach: clinical and endoscopic features. World J Gastroenterol 12: 7326-7328, 2006.

5. Pollheimer MJ, Hinterleitner TA, Pollheimer VS, Schlemmer A and Langner C: Renal cell carcinoma metastatic to the stomach: single-centre experience and literature review. BJU Int 102: 315-319, 2008.

6. Sadler GJ, Anderson MR, Moss MS and Wilson PG: Metastases from renal cell carcinoma presenting as gastrointestinal bleeding: two case reports and a review of the literature. BMC Gastroenterol 7: 4, 2007.

7. Sullivan WG, Cabot EB and Donohue RE: Metastatic renal cell carcinoma to stomach. Urology 15: 375-378, 1980.

8. Boruchowicz A, Desreumaux P, Maunoury V and Colombel JF: Dysphagia revealing esophageal and gastric metastases of renal carcinoma. Am J Gastroenterol 90: 2263-2264, 1995.

9. Blake MA, Owens A, O'Donoghue DP and MacErlean DP: Embolotherapy for massive upper gastrointestinal haemorrhage secondary to metastatic renal cell carcinoma: report of three cases. Gut 37: 835-837, 1995.

10. Odori T, Tsuboi Y, Katoh K, et al: A solitary hematogenous metastasis to the gastric wall from renal cell carcinoma four years after radical nephrectomy. J Clin Gastroenterol 26: 153-154, 1998.

11. Picchio M, Paioletti A, Santini E, Iacoponi S and Cordahi M: Gastric metastasis from renal cell carcinoma fourteen years after radical nephrectomy. Acta Chir Belg 100: 228-230, 2000.

12. Mascarenhas B, Konety B and Rubin JT: Recurrent metastatic renal cell carcinoma presenting as a bleeding gastric ulcer after a complete response to high-dose interleukin-2 treatment. Urology 57: 168, 2001

13. Kok Wee L, Shyu RY, Sheu LF, Hsieh TY, Yan JC and Chen PJ: Metastatic renal cell cancer. Gastrointest Endosc 60: 265, 2004.

14. Lamb GW, Moss J, Edwards R and Aitchison M: Case report: octreotide as an adjunct to embolisation in the management of recurrent bleeding upper gastrointestinal metastases from primary renal cell cancer. Int Urol Nephrol 37: 691-693, 2005.

15. Riviello C, Tanini I, Cipriani G, et al: Unusual gastric and pancreatic metastatic renal cell carcinoma presentation 10 years after surgery and immunotherapy: A case report and a review of literature. World J Gastroenterol 12: 5234-5236, 2006. 
16. Pezzoli A, Matarese V, Boccia S, Simone L and Gullini S: Gastrointestinal bleeding from gastric metastasis of renal cell carcinoma, treated by endoscopic polypectomy. Endoscopy 39 (Suppl 1): E52, 2007.

17. Saidi RF and Remine SG: Isolated gastric metastasis from renal cell carcinoma 10 years after radical nephrectomy. J Gastroenterol Hepatol 22: 143-144, 2007.

18. Yamamoto D, Hamada Y, Okazaki S, et al: Metastatic gastric tumor from renal cell carcinoma. Gastric Cancer 12: 170-173, 2009.

19. Kibria R, Sharma K, Ali SA and Rao P: Upper gastrointestinal bleeding revealing the stomach metastases of renal cell carcinoma. J Gastrointest Cancer 40: 51-54, 2009.

20. Sugasawa H, Ichikura T, Ono S, et al: Isolated gastric metastasis from renal cell carcinoma 19 years after radical nephrectomy. Int J Clin Oncol 15: 196-200, 2010.

21. Tiwari P, Tiwari A, Vijay M, Kumar S and Kundu AK: Upper gastro-intestinal bleeding - Rare presentation of renal cell carcinoma. Urol Ann 2: 127-129, 2010.

22. Namikawa T, Iwabu J, Kitagawa H, Okabayashi T, Kobayashi M and Hanazaki K: Solitary gastric metastasis from a renal cell carcinoma, presenting 23 years after radical nephrectomy. Endoscopy 44 (Suppl 2): E177-E178, 2012.
23. Kaplan EL and Meier P: Nonparametric estimation from incomplete observations. J Am Stat Assoc 53: 457, 1958.

24. Campoli PM, Ejima FH, Cardoso DM, et al: Metastatic cancer to the stomach. Gastric Cancer 9: 19-25, 2006.

25. Taal BG, Peterse H and Boot H: Clinical presentation, endoscopic features, and treatment of gastric metastases from breast carcinoma. Cancer 89: 2214-2221, 2000.

26. Ayantunde AA, Agrawal A, Parsons SL and Welch NT: Esophagogastric cancers secondary to a breast primary tumor do not require resection. World J Surg 31: 1597-1601, 2007.

27. Thyavihally YB, Mahantshetty U, Chamarajanagar RS, Raibhattanavar SG and Tongaonkar HB: Management of renal cell carcinoma with solitary metastasis. World J Surg Oncol 3: 48, 2005.

28. Oda I, Kondo H, Yamao T, et al: Metastatic tumors to the stomach: analysis of 54 patients diagnosed at endoscopy and 347 autopsy cases. Endoscopy 33: 507-510, 2001.

29. Motzer RJ, Michaelson MD, Rosenberg J, et al: Sunitinib efficacy against advanced renal cell carcinoma. J Urol 178: 1883-1887, 2007.

30. Suzaki N, Hiraki A, Ueoka H, et al: Gastric perforation due to metastasis from adenocarcinoma of the lung. Anticancer Res 22: 1209-1212, 2002. 